\title{
O perfil de liderança de treinadores de natação brasileiros de categorias de base
}

http://dx.doi.org/10.11606/1807-5509201700030651

\begin{tabular}{r|r} 
Varley Teoldo COSTA* & *Escola de Educacãa \\
Camila Cristina Fonseca BICALHO* & Fisica, Fisioterapia e \\
Thania Mara Teixeira Rezende FARIA* & Terapia Ocupacional, \\
Mniversidade Federal \\
Maicon Rodrigues ALBUQUERQUE* & de Minas Gerais, Belo \\
André Gustavo Pereira de ANDRADE* & Horizonte, MG, Brasil. \\
Franco NOCE $^{*}$ &
\end{tabular}

Resumo

Este estudo tem por objetivo avaliar a autopercepção de treinadores brasileiros de natação federados e verificar a existência de uma possível preferência destes profissionais por um determinado estilo de liderança de decisão e interação com seus atletas. A amostra foi composta por 66 treinadores com média de idade de $37,86( \pm 10,13)$ anos e média de tempo da prática profissional de $12,27( \pm 11,02)$ anos participantes de Campeonatos de Inverno organizados pela CBDA. Utilizou-se a Escala de Liderança Revisada para o Esporte (ELRE), versão autopercepção. Para análise estatística adotaram-se os testes de Friedman e o post hoc de Dunn com nivel de significância de $p<0,05$. Os resultados evidenciaram que, quanto ao estilo de decisão, não houve diferença significativa entre os comportamentos autocrático e democrático $(p=0,857)$. Quanto aos estilos de interação, observou-se que existem diferenças significativas entre os postos médios das dimensões treino-instrução e suporte social $(p=0,032)$, reforço positivo e suporte social $(p=0,037)$ e consideração situacional e suporte social $(p=0,042)$ e que existe uma diferença significativa entre as dimensões: reforço positivo e consideração situacional $(p=0,045)$. Conclui-se que o estilo decisão dos treinadores não pôde ser claramente delineado e que o estilo de interação está direcionado para ações que envolvem a melhoria do rendimento dos nadadores e incentivo ao alcance das metas estabelecidas.

Palavras-Chave: Estilos de Liderança; Natação; Treinador; Psicologia do Esporte.

\section{Introdução}

O rendimento esportivo é multifatorial e depende não somente da ação dos atletas, como também da família, dirigentes, treinadores e das condiçóes do ambiente ${ }^{1}$. O treinador é peça importante no processo de identificação do talento, na formação do atleta e no estabelecimento de estratégias e metas para que os atletas consigam atingir o ápice de suas potencialidades esportivas $^{1-3}$. No esporte de rendimento, variáveis como o comportamento e a capacidade de comunicação do treinador são fundamentais para uma liderança efetiva e eficaz ${ }^{2,4}$. Neste sentido, liderar equipes e atletas para que os mesmos alcancem seus objetivos é uma das competências inerentes ao cargo de treinador esportivo ${ }^{2,5}$.

Estudos sobre liderança esportiva têm sido contundentes ao afirmarem que o exercício da liderança por parte dos treinadores está solidificado em dois pilares: o alcance dos objetivos propostos e a criação de um ambiente social saudável e de confiança e respeito mútuo entre atletas e comissão técnica ${ }^{2-9}$. Autores afirmam que os treinadores precisam adequar o seu comportamento real às preferências dos atletas, as exigências da situação e ao contexto para alcançar a eficácia da liderança ${ }^{4,10,11}$. No contexto esportivo, a liderança exercida pelo treinador envolve ainda outras funções como melhoria do estado motivacional do grupo, tomadas de decisão, gestão das relaçôes interpessoais dentro do grupo, entre outras 5 .

BARROW ${ }^{12}$ conceitua a liderança como um processo comportamental capaz de influenciar nos indivíduos e grupos em direção a metas. Um dos referenciais teóricos que busca elucidar o processo de liderança 
esportiva sobre uma perspectiva interacional é o Modelo Multidimensional de Liderança no Esporte proposto por Chelladurai e Saleh ${ }^{6,13}$. O modelo considera uma interação entre as características inerentes à situação, ao próprio treinador e aos membros do grupo e é composto por três blocos de análises (antecedentes, comportamentos do líder, consequências).

No bloco de "antecedentes" analisa-se as características da situação encontradas pelo líder, as características do líder e as características do grupo de atletas. O bloco "comportamentos do líder” é denominado de comportamento exigido, comportamento atual do líder e comportamento desejado pelos atletas. O bloco "consequências do comportamento do líder" tem a intenção de avaliar o produto final do estilo de liderança adotado pelo líder (treinador) diante da equipe.

Baseado nesse modelo Chelladurai e Saleh ${ }^{6,13}$ desenvolveram um instrumento conhecido como Escala de Liderança no Esporte (ELE). Essa escala foi revisada por ZHANG et al. ${ }^{14}$ dando origem a Escala de Liderança Revisada no Esporte (ELRE), que foi validada na versão brasileira por SAMULSKI et al. ${ }^{15}$ e vem sendo utilizada para avaliar a liderança esportiva em treinadores brasileiros ${ }^{7,8,16,17}$. A ELRE possui três versóes: a versão "autopercepçãa", a versão "percepção dos atletas" e a versão "perfil ideal ou desejado". A versão "autopercepção" é a versão selecionada para este estudo.

A ELRE na versão "autopercepção" permite avaliar a percepção dos próprios treinadores sobre os seus estilos de decisão e interação que influenciam no seu perfil de liderança. Os estilos de decisão são o autocrático (8 questóes) e o democrático (12 questóes $)^{14,15}$. A dimensão autocrática avalia o comportamento do treinador caracterizado pela independência nas tomadas de decisão, ou seja, sem qualquer participação dos liderados na fixação de metas. A dimensão democrática avalia o comportamento do treinador que favorece uma maior participação dos atletas nas decisóes relativas aos objetivos do grupo, aos métodos de trabalho e às táticas e estratégias de jogo ${ }^{14,15}$.

A análise do estilo de interação é composta pelas dimensões: suporte social (8 questóes), treinoinstrução (10 questôes), reforço positivo (12 questóes) e consideração situacional (10 questóes) que avalia a autopercepção do treinador no que tange as relaçóes interacionais estabelecidas entre ele e os seus atletas. Os itens que compóem a dimensão suporte social avaliam o comportamento do treinador em relaçáo ao bem-estar individual dos atletas e a criação e manutenção de um ambiente de trabalho agradável dentro do grupo. A dimensão treino-instrução reúne itens que avaliam o comportamento do treinador na busca de um melhor rendimento dos atletas, enfatizando um treinamento estruturado e exigente com o objetivo de melhorar as capacidades técnicas e táticas de seus comandados. Os itens da dimensão reforço positivo avaliam se a conduta do treinador está voltada para a gratificação e reconhecimento do esforço do atleta, encorajando-o nas situaçóes difíceis e recompensando os bons desempenhos ${ }^{14,15}$. Por fim, os itens da dimensão consideração situacional avaliam se o treinador leva em consideraçáo os fatores situacionais do ambiente esportivo, tais como, mudanças no planejamento de treinamentos e jogos, características dos adversários e da sua equipe durante a competição, a maturidade e níveis individuais de rendimento de cada atleta, alteraçóes nos métodos de treinamento de acordo com as necessidades e especificidade encontradas no grupo de atletas ${ }^{14,15}$.

Diferentes autores, a partir do Modelo Multidimensional de Liderança no Esporte buscam elucidar os aspectos relacionados à liderança sob a perspectiva da percepção de treinadores nas categorias de base $^{7}$ e no esporte profissional ${ }^{8,16,17}$ e com atletas ${ }^{18-20}$. As evidências apontam para um número reduzido de investigaçôes que avaliaram a autopercepçáo dos treinadores. Um dos fatores que contribuem para este cenário é a dificuldade de acesso a estes profissionais e também o interesse dos mesmos em participar como voluntários de estudos científicos em que os mesmos são objeto de estudo. De acordo com Vieira et al. ${ }^{21}$, a liderança esportiva é um tema secundário de investigação no contexto da psicologia do esporte brasileiro. Dentro da temática liderança esportiva no Brasil, as investigaçóes estão centradas nas modalidades esportivas coletivas tais como o futebol ${ }^{7,8,16,17}$, o futsal $^{22}$, o voleibol ${ }^{3,23}$ e o basquete ${ }^{24,25}$ e handebol $^{26}$.

Pouco se sabe a respeito dos estilos de liderança de treinadores em modalidades esportivas individuais nas categorias de base, em especial, a natação ${ }^{27}$, expondo assim uma lacuna de conhecimento a respeito desta temática. Este estudo tem como foco contribuir na discussão da avaliação autoperceptiva de liderança dos treinadores de categoria de base da natação brasileira. Por trabalharem nos principais clubes formadores do país, estes profissionais disputam as principais competiçôes nacionais federadas e são responsáveis pela formação de novos atletas de alto rendimento para a natação do Brasil. 
No caso específico na natação, pela estrutura competitiva existente no Brasil, o treinador na categoria de base tem que trabalhar com equipes de jovens em diferentes categorias e estilos de nado ${ }^{28}$, isto faz com que este profissional no seu trabalho diário tenha que adotar diferentes estilos de decisão e interação para adaptar-se e conseguir liderar o seu grupo de atletas. $\mathrm{O}$ que se pretende investigar é qual a percepção que eles possuem sobre o seu estilo de liderança trazendo uma reflexão sobre os impactos da adoção de um determinado estilo no processo formativo de jovens atletas para a natação de base do Brasil.

Até o presente momento, não foram encontradas evidências científicas que permitam estabelecer um perfil de liderança de treinadores que conduza com eficácia o processo de formação de atletas nas categorias de base da natação brasileira. Percebe-se que em geral, os atletas estabelecem relaçóes com os treinadores para aprender habilidades, técnicas e táticas, para se sentir competente e bem sucedido, e para obter a satisfaçáo de seu esporte. Em contrapartida, os treinadores estabelecem relaçóes com os atletas para compartilhar conhecimento e experiência, para apoiar o atleta a alcançar o seu potencial, e para alcançar o sucesso e satisfação pessoal ${ }^{29}$.

Os profissionais que trabalham com atletas em formação, frequentemente, adotam estilos de liderança e gestáo de equipes incompatíveis com o processo de formação nas categorias de base. Sabe-se pela literatura que jovens esportistas em processo de formação necessitam de apoio social, estão ainda em processo de formação da sua personalidade, são inseguros quanto a suas potencialidades e desafios dentro e fora do contexto esportivo ${ }^{30}$.

Assim, o treinador de natação, que exerce a função de líder no contexto desta modalidade, necessita possuir os conhecimentos sobre os aspectos técnicos, táticos, físicos, psicológicos e sociais inerentes à natação ${ }^{3}$. THON et al. ${ }^{27}$ durante uma competição estadual com atletas e treinadores da natação brasileira, ao analisar a equipe campeá, identificaram a satisfação dos atletas em relação ao estilo de liderança do treinador, dado que reforça a importância desta competência nos profissionais que atuam nesta modalidade. De acordo como os próprios autores supracitados, o estudo apresentou limitações como o fato dos resultados náo poderem ser generalizados para toda a realidade brasileira, uma vez que foram avaliados apenas atletas e técnicos de um único estado e a utilização de uma versão da Escala de Liderança do Desporto náo validada para o português do Brasil ${ }^{27}$.

Diante dos argumentos expostos acima e da importância de promover avanços na compreensão do constructo psicológico da liderança em treinadores da categoria de base, este estudo tem por objetivo avaliar a autopercepção de treinadores brasileiros de natação federados e verificar a existência de uma possível preferência destes profissionais por um determinado estilo de liderança de decisão e interação com seus atletas.

\section{Método}

\section{Cuidados éticos}

O estudo foi aprovado pelo Comitê de ética da UFMG pelo parecer número 10890812.0000.5149. Um termo de compromisso livre e esclarecido foi entregue aos participantes voluntários dessa pesquisa antes do preenchimento de qualquer questionário. Todos os participantes assinaram esse termo, estando cientes que poderiam sem constrangimento abandonar o procedimento experimental.

\section{Amostra}

Participaram do estudo 66 treinadores federados, do sexo masculino, que trabalham nas categorias de base de clubes de natação. Os treinadores voluntários deste estudo apresentaram média de idade de 37,86 $( \pm 10,13)$ anos e média de tempo da prática profissional de $12,27( \pm 11,02)$ anos, sendo que a média do tempo de envolvimento com a natação, contabilizando o tempo direto como atleta ou outros cargos, é de 23,26 ( $\pm 9,39)$ anos.

Foram avaliados treinadores de todas as regióes do Brasil, participantes do Campeonato Brasileiro Juvenil de Inverno, da Competição Sudeste Pré-mirim e Mirim de Inverno e da Competição Sudeste Petiz e Infantil de Inverno, todos organizados pela Confederação Brasileira de Desportos Aquáticos (CBDA). Observouse dentro da amostra analisada que $91 \%$ dos treinadores entrevistados exerciam esta função em 3 ou mais categorias nos clubes em que trabalhavam. 


\section{Instrumentos}

Como instrumento de medida para avaliação da liderança dos treinadores foi utilizada a ELRE versão "autopercepção" validada na versão brasileira por SAMULSKi et al. ${ }^{15}$. A ELRE na versão "autopercepção" é composta de 60 itens que são avaliados dentro de uma escala Likert de cinco pontos com as seguintes opçôes de resposta: sempre (100\%), frequentemente (75\%), ocasionalmente (50\%), raramente $(25 \%)$ e nunca (0\%). De acordo com esse instrumento, é possível estabelecer os estilos de decisão e interação dos treinadores.

A consistência interna do instrumento, avaliada através do índice de Alpha Cronbach, neste estudo no geral foi de $\alpha=0,879$. A literatura recomenda valores acima de Alpha de Cronbach superiores a 0,700 para garantir a confiabilidade do instrumento na amostragem testada ${ }^{31}$.

\section{Procedimentos de coleta de dados}

Todos os clubes e seus respectivos treinadores foram contatados previamente pelos pesquisadores responsáveis com o objetivo de esclarecer os objetivos da pesquisa e fazer o convite para a participação no estudo

Foi preenchido pelos treinadores o questionário de identificação demográfica a fim de traçar o perfil dos participantes, constando idade, sexo, tempo de atuação como treinador, tempo de contato com a natação e categorias nas quais trabalha e já trabalhou. Em seguida, os treinadores responderam a Escala de Liderança Revisada do Esporte (ELRE), versão autopercepção.
As coletas foram realizadas em locais apropriados dentro dos hotéis e alojamentos das equipes durante a competição durante as três competiçóes anteriormente mencionadas. Durante as coletas não houve nenhum tipo de interferência de terceiros sendo que os treinadores preencheram os questionários sem qualquer restrição de tempo para o registro de suas respostas.

\section{Procedimentos estatístico}

Os dados relativos à caracterização da amostra foram analisados de forma descritiva utilizando-se os valores de média, desvio padrão. $\mathrm{O}$ coeficiente Alpha Cronbach foi utilizado para analisar a consistência interna do instrumento ${ }^{31}$. Para análise da normalidade dos dados foi utilizado o teste de Komolgorov-Smirnov, o resultado indicou a utilização de procedimentos náo paramétricos. Utilizou-se o teste de Friedman para a comparação entre os postos médios de cada dimensão ${ }^{32,33}$. O objetivo deste procedimento é verificar se existem diferenças estatisticamente significativas entre os estilos de liderança por parte dos treinadores em relação aos seus perfis de comando.

Os procedimentos de análise dos dados foram realizados no pacote estatístico SPSS ${ }^{34}$ (Statistical Package for Social Science) for Windows , versão 18.0, adotando o nível de significância de $\mathrm{p} \leq 0,05$.

Para localizar onde estão estas possíveis diferenças entre as dimensóes foi realizado o teste Post Hoc de Dunn no pacote estatístico Graph Pad Prism ${ }^{\circledR}$ for Windows version 5.0.

\section{Resultados}

Os 60 itens da ELRE foram analisados quanto aos estilos de decisão e interação dentro das seis dimensôes: autocrático, democrático, treino-instrução, suporte social, reforço positivo e consideração situacional. A Tabela 1 apresenta os valores dos postos médios de cada um dos construtos da ELRE.

Os valores dos postos médios demonstram o nível de percepção dos treinadores de base a respeito do próprio estilo de liderança. Observa-se que, em relação às dimensóes que compóem o estilo de interação, os treinadores utilizam mais os aspectos de reforço positivo $(4,99)$ e treino-instrução $(4,98)$, seguidos de consideração situacional $(4,25)$ e suporte social $(3,17)$. Quanto ao estilo de decisão os valores de postos médios para comportamentos autocráticos foram de $(1,72)$ e democráticos $(1,52)$.

De acordo com a Tabela 2, foram encontradas diferenças significativas entre os estilos de liderança dos treinadores $(\mathrm{p}=0,001)$, sendo que essas diferenças foram posteriormente localizadas utilizando-se o Post Hoc de Dunn (Tabela 3).

Foi também encontrada diferença significativa entre as dimensóes: reforço positivo e consideraçáo situacional $(\mathrm{p}=0,045)$.

Com relação aos estilos de decisão autocrático e democrático, observa-se que os valores dos postos médios são baixos e estatisticamente semelhantes, ou seja, não existe diferença significativa entre 
eles $(\mathrm{p}=0,857)$ o que não permite identificar um estilo de decisão predominante de liderança nestes treinadores avaliados. $\mathrm{O}$ escore da dimensão suporte social foi estaticamente inferior aos valores de todas as dimensôes que avaliam o estilo de interação do treinador, treino-instrução $(\mathrm{p}=0,032)$, reforço positivo $(\mathrm{p}=0,037)$ e consideração situacional $(\mathrm{p}=0,042)$, o que demonstra uma menor percepção da importância desta dimensão para os treinadores avaliados.

TABELA 1 - Resultado dos postos médios do nível de percepção dos treinadores por dimensão.

\begin{tabular}{llc}
\hline Dimensão & & Posto Médio \\
\hline \multirow{2}{*}{ Estilo de Decisão } & Comportamento democrático & 1,52 \\
\cline { 2 - 3 } & Comportamento autocrático & 1,72 \\
\hline \multirow{3}{*}{ Estilo de Interação } & Suporte social & 3,17 \\
\cline { 2 - 3 } & Consideração situacional & 4,25 \\
\cline { 2 - 3 } & Treino-instrução & 4,98 \\
\cline { 2 - 3 } & Reforço positivo & 4,99 \\
\hline
\end{tabular}

TABELA 2 - Comparação entre os valores médios das dimensões da ELRE versão “autopercepção".

\begin{tabular}{lc}
\hline \multicolumn{1}{l}{ TESTE DE FRIEDMAN } \\
\hline $\mathrm{N}$ & 66 \\
\hline Qui-quadrado & 254,6 \\
\hline Graus de liberdade & 5 \\
\hline Significância & 0,001 \\
\hline
\end{tabular}

TABELA 3 - Comparações múltiplas entre os valores médios das dimensões da ELRE versão “autopercepção”.

\begin{tabular}{lcc}
\hline Comparaçóes entre as dimensóes & Dif. entre na soma dos ranks & Valor $\mathbf{p}$ \\
\hline Estilo de Decisão & & \\
\hline Democrático x Autocrático & $-13,00$ & 0,857 \\
\hline Estilo de Interação & 125,00 & \\
\hline Treino Instrução x Sup.Social & $-14,50$ & $0,032^{*}$ \\
\hline Treino Instrução x Ref. Positivo & 53,50 & 0,451 \\
\hline Treino Instrução x C.Situacional & $-139,50$ & 0,357 \\
\hline Suporte Social x Ref. Positivo & $-71,50$ & $0,037^{*}$ \\
\hline Suporte Social x C. Situacional & 68,00 & $0,042^{*}$ \\
\hline Reforço Positivo xC.Situacional & & $0,045^{*}$
\end{tabular}

\section{(1)}




\section{Discussão}

O objetivo deste estudo foi avaliar a autopercepção de treinadores brasileiros de nataçáo federados e verificar a existência de uma possível preferência destes profissionais por um determinado estilo de liderança de decisão e interação com seus atletas.

Até o presente momento não foram identificados estudos que avaliaram a autopercepção de liderança dos treinadores de natação nas categorias de base, sendo assim a discussão dos resultados deste estudo apresenta um componente limitador que é a comparação entre estudos que avaliaram os estilos de liderança adotados por treinadores de natação das categorias de base de profissionais de diferentes países e contextos esportivos através da avaliação da sua autopercepção. Desta forma em função do atual "estado da arte" envolvendo a temática os resultados do presente estudo serão confrontados com estudos que avaliaram a autopercepçáo de treinadores de categoria de base em outras modalidades esportivas e também com estudos que avaliaram a percepção dos atletas sobre o estilo de liderança de seus treinadores.

Quanto ao estilo de decisão autocrático ou democrático, verificou-se neste estudo, que os valores dos postos médios são baixos e que não existe diferença estatística entre eles; ou seja, não é possível explicitar a predominância de um tipo de conduta decisória destes treinadores de natação de categoria de base brasileiros que foram avaliados.

Os resultados desse estudo não corroboram com estudos que utilizaram a ELRE, versão autopercepção, em treinadores de categorias de base de outras modalidades esportivas. Costa et al. ${ }^{7}$, avaliaram o perfil de liderança de treinadores de futebol brasileiros de categorias de base e identificaram que os treinadores adotam primordialmente comportamentos mais voltados para a autocracia. Resultados semelhantes foram encontrados para treinadores de futebol profissional que disputam competiçóes estaduais e nacionais ${ }^{8,16,17}$ que também identificaram uma autopercepção dos treinadores direcionada para o perfil autocrata. Apesar dos estudos supracitados terem utilizado um design metodológico de avaliação semelhante, o fato de existirem poucas investigações sobre autopercepção de treinadores esportivos de categoria de base, não permite uma conclusão definitiva sobre o tema. Em síntese o que se pode inferir é que os estudos que avaliam liderança sob a perspectiva da autopercepçáo de treinadores são incipientes e necessitam avançar especialmente no que tange a adoção de novas técnicas de mensuração longitudinal e situacional destes estilos decisórios adotados pelos técnicos. As poucas evidências ${ }^{11}$ permitem hipotetizar que possam existir diferenças na autopercepção de treinadores esportivos, no que tange o estilo de decisão, em função dos mesmos trabalharem com modalidades individuais ou coletivas. Treinadores de esportes individuais, como a natação, do ponto de vista organizacional, têm sob sua responsabilidade e comando um número menor de atletas, o que gera interações menos complexas entre o líder e os liderados ${ }^{35}$.

Este tipo de contexto organizacional esportivo onde o treinador de natação possui uma relação direta mais próxima do atleta no dia a dia de treinamento e competição pode favorecer o aparecimento de estilos de decisão mais democráticos ou autocráticos, dependendo do grau de maturidade dos atletas. Estudos têm evidenciado que o grau de maturidade dos atletas e a complexidade organizacional da equipe favorecem a adoção por parte dos treinadores de um determinado estilo de decisão que tem como objetivo otimizar a eficácia do seu trabalho e o gerenciamento da equipe ${ }^{26,36}$.

Comparando os resultados deste estudo com trabalhos que avaliaram a percepçáo de atletas sobre o perfil de treinadores em esportes aquáticos. Os resultados encontrados neste estudo também apresentaram divergências com demais em estudos realizados na natação de base ${ }^{27}$, natação categoria absoluta $^{27}$ e nado sincronizado ${ }^{29}$. Estes identificaram que o comportamento democrático foi definido como preferido pelos atletas no perfil de liderança dos treinadores destas modalidades ${ }^{27,29}$. Observase que apesar dos treinadores não possuírem uma autopercepção definida sobre o seu estilo decisão, atletas de natação e de outras modalidades aquáticas tem evidenciado que uma preferência por treinadores que adotam um estilo de decisão democrática.

Pressupóe-se nesse estudo, que os baixos valores de posto médio e a ausência de um estilo de decisão predominante entre os comportamentos autocrático e democrático dos treinadores podem estar relacionados ao contexto esportivo e as condiçóes de trabalho nas categorias de base da natação brasileira. A natação competitiva no Brasil se desenvolve principalmente no âmbito dos clubes federados e esses, frequentemente, não são capazes de contratar um treinador específico para cada categoria 
ou estilo de prova da natação devido à escassez de recursos financeiros para investir na modalidade ${ }^{28}$. Sendo assim é comum a contratação de treinadores na categoria de base que acabam tendo que atuar em diferentes faixas etárias e estilos de nado. Os resultados dos dados demográficos apontam que $91 \%$ da amostragem avaliada trabalham em mais de 3 categorias e isto pode ter influenciado a não identificação uma predominância por um estilo de decisão tendo em vista que estes profissionais

MARTENS $^{37}$ reforça que muitas vezes o líder para ser efetivo necessita tramitar por estilos de decisão autocráticos e democráticos mediante a característica do grupo que está sob sua responsabilidade. Evidências apontam que o comportamento dos treinadores é influenciado tanto pela modalidade em questão ${ }^{7,11,17}$, quanto pelo sexo ${ }^{28}$ e nível de experiência ${ }^{29}$ dos atletas.

Em relação ao estilo de interação, observa-se nos resultados (Tabela 3) que a dimensão suporte social é percebida em menor escala na conduta dos treinadores quando comparada às dimensóes de reforço positivo, treino-instrução e consideração situacional $(p \leq 0,05)$. Este resultado encontrado com treinadores de competiçóes nacionais corrobora com os estudos realizados no futebol de base ${ }^{7}$ e profissional ${ }^{8,17}$, em que o estilo de interação treino-instruçáo foi o preferido na autopercepção dos treinadores.

Estudo de Nascimento e Vieira ${ }^{22}$ identificou que as características de suporte social, reforço e instruções durante os treinamentos e jogos são mais frequentes em treinadores de equipes que disputam campeonatos estaduais quando comparados aos seus pares que disputam campeonatos nacionais. Quanto aos estilos de interaçáo, os treinadores desse estudo ${ }^{22}$ apresentam predominantemente os comportamentos de reforço positivo, treinoinstrução e consideração situacional.

A avaliaçáo do perfil de liderança de treinadores proposta por THON et al. ${ }^{27}$, identificaram que os atletas apresentaram preferência a treinadores mais voltados para melhoria do desempenho (treino-instrução).

Observa-se uma congruência entre a autopercepção dos treinadores e a percepção dos atletas no que tange o estilo de interação de liderança esportiva. Apesar do reduzido número de estudos dentro do contexto da natação ${ }^{3,27}$, fica evidente a preferência pela dimensão treino-instrução. Estes resultados também são evidenciados em outros estudos envolvendo a auto percepção de treinadores de base $^{7}$ e profissional ${ }^{8}$ e também a autopercepção de atletas nestes dois contextos ${ }^{35}$.
Também fica evidente nestes estudos ${ }^{3,27}$, relacionados com o esporte competitivo, uma menor percepção dos pares envolvidos (treinadores e atletas) sobre a importância da dimensão suporte social.

A dimensão suporte social, caracterizada pelo interesse do treinador acerca dos atletas e do seu bem-estar, tem como objetivo manter um ambiente agradável no grupo e facilitar as relaçóes interpessoais entre os pares e dar suporte social para as necessidades e anseios dos atletas ${ }^{4,23}$. A dimensão suporte social também gera vínculos de curto, médio e longo prazo na relação treinador atletas. Por se tratar de treinadores que trabalham nas categorias de base com jovens em processo de formação, o resultado encontrado neste estudo traz certa preocupação no que tange o comprometimento dos treinadores o fornecimento de suporte social aos jovens atletas.

Compreende-se a importância dessa dimensão, uma vez que os treinadores têm um papel fundamental no desenvolvimento e na formaçáo humanista destes atletas ${ }^{23,27}$. Apesar de estudos evidenciarem a dimensão suporte social no estilo de interação como a predominante na visão dos próprios treinadores ${ }^{22,38}$, os aspectos sociais e de grupo nas equipes esportivas são, em geral, levados em menor consideração perante as outras dimensóes (reforço, situacional, treino-instrução) $)^{7,16,18,20,24}$.

Nesse sentido a análise deve ser criteriosa, já que a não predominância da dimensão suporte social no estilo de liderança náo implica em desconsideraçấo efetiva dos aspectos sociais. Isso é explicado, segundo Costa e SAmulski ${ }^{16}$ e Hoshino et al. ${ }^{20}$ pelo fato de que à medida que se aumentam os níveis de habilidade e da competitividade das equipes, aumenta-se também o nível de cobrança por resultados e diminuem-se as açóes humanistas do treinador dentro do grupo de atletas.

Como limitaçôes deste estudo, destaca-se o fato de ter sido feita somente uma avaliação unilateral, baseada somente na autopercepção dos treinadores diminui o impacto destes resultados, tendo que vista que a percepção de atletas e dirigentes sobre o perfil de seus treinadores também pode contribuir para uma análise mais eficaz da variável liderança no contexto esportivo.

Outra limitação é que os treinadores avaliados atuam, em grande parte, em mais de uma categoria de base. Esta limitaçáo é decorrente do contexto e das condiçóes socioeconômicas da natação brasileira precisam ser analisados com atenção. Apesar destes fatores descritos acima os resultados deste estudo permitem uma maior compreensão sobre as nuances 
que circundam o perfil de liderança de treinadores de base na natação brasileira e contribuem para a discussão acerca da temática.

Em síntese, a questão dos treinadores de natação avaliados nos remete ao fato de que o perfil de tomada de decisão centralizada (autocrática) ou compartilhada (democrática) não está definido para esta amostragem de profissionais avaliados. $\mathrm{O}$ resultado quanto ao estilo de interaçáo treinadoratleta reforça que os treinadores de categoria de base na natação se preocupam em otimizar o rendimento de seus atletas e procuram incentiválos positivamente no alcance das metas estabelecidas, levando em consideração as variáveis situacionais do esporte.

Entretanto, por se tratarem de atletas em período de formação, cabe alertar aos treinadores que não devem se descuidar dos aspectos relacionados ao suporte social dentro e fora do contexto esportivo. A avaliação da autopercepção destes profissionais é de suma importância para que os mesmos examinem e reflitam sobre suas condutas e procurem estratégias de liderança e gerenciamento cada vez mais eficientes para conduzir suas equipes de natação e auxiliar seus comandados a serem melhores atletas e cidadãos.

\section{Abstract}

\section{Leadership profile of youth categories coaches from Brazil}

This study aims to valuate the perception of Brazilian Federated swimming coaches and verify the existence of a possible preference of these professionals for a particular leadership style of decision and interaction with their athletes. The sample consisted of 66 coaches with an average age of $37.86( \pm 10.13)$ years and average professional practice of $12.27( \pm 11.02)$ years participating in Winter Tournaments organized by the CBDA. The self-perception version of the Revised Leadership Scale for Sport (ELRE) was used in the study. For the Statistical analysis, the Friedman test and post hoc Dunn were adopted with a significance level of $p<0.05$. The results showed that, as for the style of decision, there was no significant difference between autocratic and democratic $(p=0.857)$ behaviors. As for styles of interaction, there are significant differences between the mean rank of the dimensions instruction-training and social support ( $p=0.032)$; positive reinforcement and social support $(p=0.037)$; and situational consideration and social support $(p=0.042)$ and that there is a significant difference between the dimensions: positive reinforcement and situational consideration $(p=0.045)$. It can be concluded that the coaches' style of decision could not be clearly delineated and that the style of interaction is directed towards actions that involve improving the performance of swimmers and encouraging the achievement of established goals.

KEYWORDS: Leadership style; Swimming; Coach; Sport Psychology.

\section{Referências}

1. Durand-Bush N, Salmela JH. The development and maintenance of expert athletic performance: perceptions of world and Olympic champions. J Appl Sport Psyc. 2002;14(3):154-71.

2. Brandão MRF, Carchan D. Comportamento preferido de liderança e sua influência no desempenho dos atletas. Motricidade. 2002;6(1):53-69.

3. Samulski DM, Pussieldi GA, Noce F. Estudo dos estilos de liderança e características preferidas por treinadores de voleibol e de natação. In: Silami-Garcia E, Lemos KLM, Greco PJ, organizadores. Temas atuais em educação física e esportes III. Belo Horizonte: Health; 1998. Cap. 9; p. 139-54.

4. Hampson R, Jowett S. Effects of coach leadership and coach-athlete relationship on collective efficacy. Scand J Med Sci Sports. 2014;24(2):454-60.

5. Trenz RC, Zusho A. Competitive swimmers' perception of motivational climate and their personal achievement goals. Intern J Sport Science \& Coach. 2011;6(3):433-43. 
6. Chelladurai P, Saleh SD. Dimensions of leader behavior in sports: development of a leadership scale. J Sport Psychol. 1980;2(1):34-45.

7. 7. Costa, IT, Samulski, DM, Costa VT. Análise do perfil de liderança dos treinadores das categorias de base do futebol brasileiro. Rev Bras Educ Fís Esp. 2009;23(3):185-94.

8. Costa IT, Samulski D, Marques M. Análise do perfil de liderança dos treinadores de futebol do Campeonato Mineiro 2005. Rev Bras Ci e Mov. 2006;14(3):55-62.

9. Chelladurai P. Leadership. In: Singer RN, Murphey M, Tennant LK. Handbook of Research on Sport Psychology. New York: Macmilliam; 1993.

10. Vieira LF, Oliveira LP, Vissoci JR. O treinador e o processo de interação psicológica. In: Brandão, M., organizador. O treinador e a psicologia do esporte. São Paulo: Editora Athenéu; 2010.

11. Lorimer R, Jowett S. Empathic accuracy in coach-athlete dyads who participate in team and individual sports. Psychol Sport Exerc. 2009;10(1):152-8.

12. Barrow, J. The variables of leadership: a review and conceptual framework. Acad Manage Rev. 1977;2(2):231-51.

13. Chelladurai P, Saleh S. Preferred leadership in sports. Can J Appl Sport Sci. 1978;3:85-92.

14. Zhang J, Jensen BE, Mann BL. Modification and revision of the Leadership Scale for Sport. J Sport Behav. 1997;20(1):105-22.

15. Samulski D, Lopes MC, Costa IT. Validação da escala de liderança revisada para o esporte: versão autopercepçâo [CD-ROOM]. Anais do IV Fórum Brasil Esporte: buscando a excelência esportiva; 2006; Belo Horizonte. [local, data e editora desconhecidos]

16. Costa IT, Samulski DM, Costa VT. Perfil de liderança para treinadores de futebol na visão de treinadores do campeonato brasileiro. Rev Educ Fís. 2010;21(1):59-68.

17. Costa IT, Samulski D. O perfil de liderança dos treinadores de futebol do Campeonato Brasileiro Série A/2005. Rev Bras Educ Fís Esp. 2006;20(3):175-84.

18. Sonoo CN, Hoshino EF, Vieira LF. Liderança esportiva: estudo da percepção de atletas e técnicos no contexto competitivo. Psicol Teor Prát. 2008;10(2):68-82.

19. Beam J, Sewatka T, Wilson W. Preferred Leadership of NCAA division I and II intercollegiate student-athletes. J Sport Behav. 2004:27(1):1-17.

20. Hoshino EF, Sonoo CN, Vieira LF. Perfil de liderança: uma análise no contexto esportivo de treinamento e competição. Rev Educ Fís. 2007;18(1):77-83.

21. Vieira LF, Andrade JRNJ, Vieira JLL. O estado da arte da pesquisa em Psicologia do Esporte no Brasil. Rev Psic Dep. 2013;22(2):501-7.

22. Nascimento JRA, Vieira LF. Coesão de grupo e liderança do treinador em função do nível competitivo das equipes: um estudo no contexto do futsal paranaense. Rev Bras Cineantropom Desempenho Hum. 2013;15(1):89-102.

23. Lopes M, Samulski D, Noce F. Análise do perfil ideal do treinador de voleibol das seleçôes brasileiras juvenis. Rev Bras Ciência e Movimento. 2004;12(4):51-5.

24. Alba GR, Toigo T, Barcellos PFP. Percepção de atletas profissionais de basquetebol sobre o estilo de liderança do técnico. Rev Bras Ciências do Esporte. 2010;32(1):143-59.

25. Simôes AC, Serassuelo HJ, Azevedo LDCJ. Comportamento ideológico de liderança de professores-técnicos líderes de equipes esportivas escolares-modalidade basquetebol. Rev Bras Cineantropom Desempenho Hum. 2007;9(1):76-83.

26. Lee Y, Kim SH, Joon-ho K. Coach leadership effect on elite handball players' psychological empowerment and organizational citizenship behavior. Intern J Sport Science \& Coach. 2013;8(2):327-42.

27. Thon RA, Passos PCB, Costa LCA, Prates MEF, Nascimento Junior JRA, Vieira LF. Estilo de liderança no contexto de treinadores de natação do Paraná. Rev Bras Cineantropom Desempenho Hum. 2012;14(5):527-34.

28. Cavalcanti V, Dantas AR, Ferreira IJ, Santos LR. Categorizaçấo dos treinadores de nataçâo da cidade de Manaus/AM. R Min Educ Fís. 2012;No Espec(1):2136-45.

29. Jowett S, Nezlek J. Relationship interdependence and satisfaction with important outcomes in coach-athlete dyads. J Social Personal Relat. 2012;29(3):287-301.

30. Ardua CM, Márquez S. Relação entre estilos de liderança do treinador e rendimento na natação sincronizada. Fit Perform J. 2007;6(6):394-7.

31. Cronbach IJ. Coefficient alpha and the internal structure of tests. Psycho. 1951;16(3):297-335.

32. Callegari-Jacques SM. Bioestatística: princípios e aplicaçōes. Porto Alegre: Artmed; 2007.

33. Pasquali L. Instrumentação psicológica: fundamentos e práticas. Porto Alegre: Artmed; 2010.

34. Dancey CP, Reidy J. Estatística sem matemática para psicologia: usando SPSS para Windows. Vol 3. Porto Alegre: Artmed; 2006. 
35. Alfermann D, Lee MJ, Würth S. Perceived leadership behavior and motivational climate as antecedents of adolescent athletes' skill development. Athl Insight. 2005;7(2):14-36.

36. Chelladurai P, Carron A. Athletic maturity and preferred leadership. J Sport Psychol. 1983;5(4):371-80.

37. Martens R. Coaches guide to sport psychology. Champain: Human Kinectis; 1987.

38. Jambor EA, Zhang JJ. Investigating leadership, gender, and coaching level using the Revised Leadership for Sport Scale. J Sport Behav. 1997;20(3):313-9.

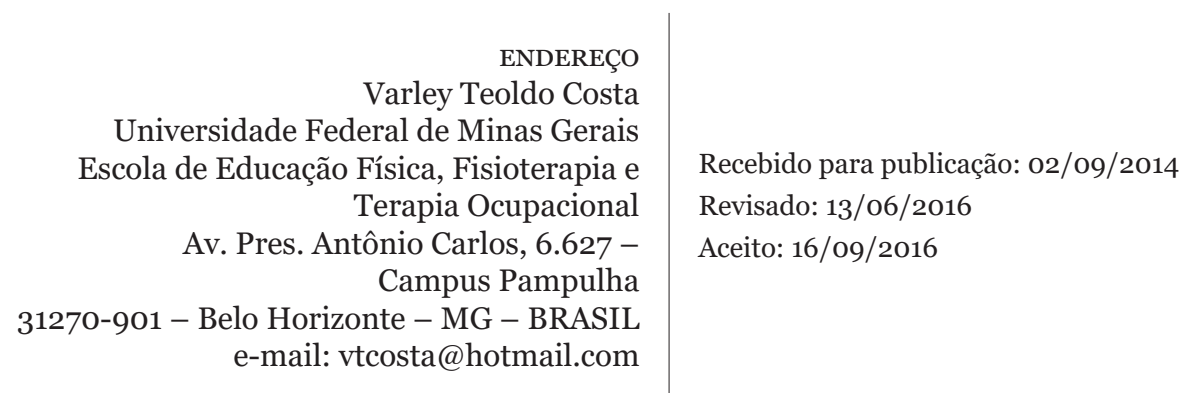

